(C)2006 IEEE. Personal use of this material is permitted. However, permission to reprint/republish this material for advertising or promotional purposes or for creating new collective works for resale or redistribution to servers or lists, or to reuse any copyrighted component of this work in other works must be obtained from the IEEE. 


\title{
High performance hydrogen selective membranes prepared using rapid processing method.
}

\author{
Suraj Gopalakrishnan $*^{\ddagger}$, Balagopal N. Nair ${ }^{\dagger}$, Shin-ichi Nakao \\ *ARC Centre for Functional Nanomaterials, University of Queensland, Brisbane QLD 4072, Australia. \\ Email: s.gopalakrishnan@uq.edu.au \\ ${ }^{\dagger}$ Noritake Company Limited, Miyushi higashiyama 300, Aichi 470-0293, Japan. \\ Email: B.Nair@curtin.edu.au \\ ${ }^{\ddagger}$ Department of Chemical System Engineering, University of Tokyo, Bunkyo-ku, Tokyo 113-8656, Japan. \\ E-mail: maku@chemsys.t.u-tokyo.ac.jp
}

\begin{abstract}
The production of hydrogen using membrane based reforming technology is one important application where the membrane is required to withstand high temperatures and pressures to achieve maximum efficiency from an equilibriumlimited reaction. Microporous silica membranes offer a viable alternative to polymer and metal composite membranes. The processing of silica membranes including sol-gel and chemical vapor deposition (CVD) methods are discussed adequately in the literature. The Sol-gel method allows for the precise control of pore structure while CVD results in chemically homogenous deposits inside the porous substrates to yield better selectivity. The main problem associated with these methods is the long processing times to prepare these membranes, resulting in increased cost of production for the processing of large batches. Here we report an advance in membrane processing that could drastically reduce membrane processing time without compromising performance.
\end{abstract}

Keywords - hydrogen-selective; silica membrane; hybrid processing

\section{INTRODUCTION}

Hydrogen is widely used in various industries, such as the chemical industry, oil refining and petrochemical industries and is also expected to be widely used as an alternative energy source and energy carrier in the near future [1]. Fuel cells, which have seen remarkable development in the last decade, have the advantage of high efficiency, low emissions and have been adapted for transportation as well as for both stationary and portable power generation. Fuel cells require hydrogen as their primary fuel which could be derived from various natural resources through one of the following three major techniques - steam reforming, partial oxidation reforming and autothermal reforming. Among these, steam reforming is the most common reaction for producing hydrogen in which steam reacts with fuel (eg. Natural gas) in the presence of a catalyst to produce hydrogen, carbon monoxide and carbondioxide [2].

$$
\begin{aligned}
& \mathrm{CH}_{4}+\mathrm{H}_{2} \mathrm{O} \leftrightarrow \mathrm{CO}+3 \mathrm{H}_{2} \\
& \mathrm{CO}+\mathrm{H}_{2} \mathrm{O} \leftrightarrow \mathrm{CO}_{2}+\mathrm{H}_{2}
\end{aligned}
$$

Thermodynamics of this reaction is well known to favourably proceed at temperatures $>1073 \mathrm{~K}$ and lower pressures. If $\mathrm{H}_{2}$ can be selectively removed from the system (as in membrane reactors), the thermodynamic equilibrium can be shifted to the product side resulting in higher conversions of $\mathrm{CH}_{4}$ to $\mathrm{H}_{2}$ even at lower temperatures of $\sim 773$ $\mathrm{K}$.

Microporous ceramic membranes or their ability to separate small gaseous molecules such as hydrogen from gas mixtures, together with their intrinsic thermal, chemical and structural stability, proposes them to be used in rigorus membrane reactor applications. An important prerequisite for such applications is that the membrane should posses high permselectivity and faster permeation through them.

Silica membranes display high combined values of $\mathrm{H}_{2}$ flux and selectivity. Based on their mode of preparation, silica membranes can conveniently be divided into sol-gel membranes and CVD membranes. Sol-gel membranes were prepared by applying a sol made from an alkoxide precursor over a mesorporous support, (typically a gamma-alumina substrate) and firing this layer at $\sim 873 \mathrm{~K}$. The preparation and final properties of such a membrane mainly depends on the sol chemistry [3, 4]. CVD membranes were prepared by the decomposition or reaction of gas phase precursors inside or near the pores of the supports. Here, the final membrane properties depends strongly on the preparation conditions (gas composition, temperature and pressure) and the support structure. Generally, compared to sol-gel membranes, CVD membranes yields better selectivity but with lower flux through them. Sol-gel membrane production involves numerous layer formation while CVD membranes could be produced with fewer processing steps. And since they are confined inside the pores of the substrate, they are well protected and are free from thermal cracking and peeling. The quality of the substrate plays an important factor in both these processes, especially when very thin membranes are required.

We have been working the area of sol-gel membranes for the last decade [3-5]. Recently, we have succesfully prepared CVD capillary membranes [6], as well as membrane modules 
(made by arranging several capillary substrates inside a modular casing) with excellent permselectivity and performance [7]. An attenpt was also made to integrate both sol-gel and CVD methods to derive hybrid membranes with better performance.

\section{EXPERIMENT}

Alpha-alumina capillary tubes with an average pore size of $100 \mathrm{~nm}$ (35 cm long; $2.7 \mathrm{~mm}$ diameter) supplied by NOK Co. Ltd., Japan, was used as support. For preparing shortmembranes, both ends of the substrate were glass-coated leaving $5 \mathrm{~cm}$ in the middle portion as membrane area, which was further coated with boehmite sol $[3,6]$ followed by calcination at $873 \mathrm{~K}$ to produce a gamma-alumina layer. For large-membranes, $23 \mathrm{~cm}$ on the middle region was used as membrane area. Module was fabricated by arranging three short-gamma-alumina capillary substrates (pitch $=4.5 \mathrm{~mm}$ ) inside a dense silica tubular casing $(19 \mathrm{~mm})$ and attaching them to the casing on either ends by glass sealing (Fig. 1). This module was kept inside a high temperature reactor for CVD reaction. Schematic representation of a simultaneous $\mathrm{CVD} /$ measurement apparatus is given in Fig. 2. Tetramethyl orthosilicate (TMOS) was fed through the outer side of the module (flow rate $=0.98 \mathrm{~mol} \mathrm{~m}^{-2}$ ), which reaches the capillary substrate through slots on either sides of the dense casing. Oxygen was introduced through the inner side and reaction takes place inside the gamma-alumina layer (counter-

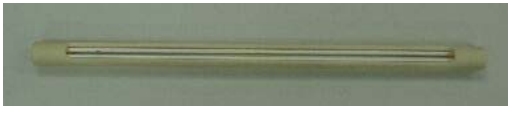

Figure. 1: Arrangement of $\gamma$-alumina capillary substrates inside the module. Dimensions OD: $2.7 \mathrm{~mm}$ ID: $1.9 \mathrm{~mm}$ Effective membrane area $=14.1 \times 10^{-4} \mathrm{~m}^{2}$.
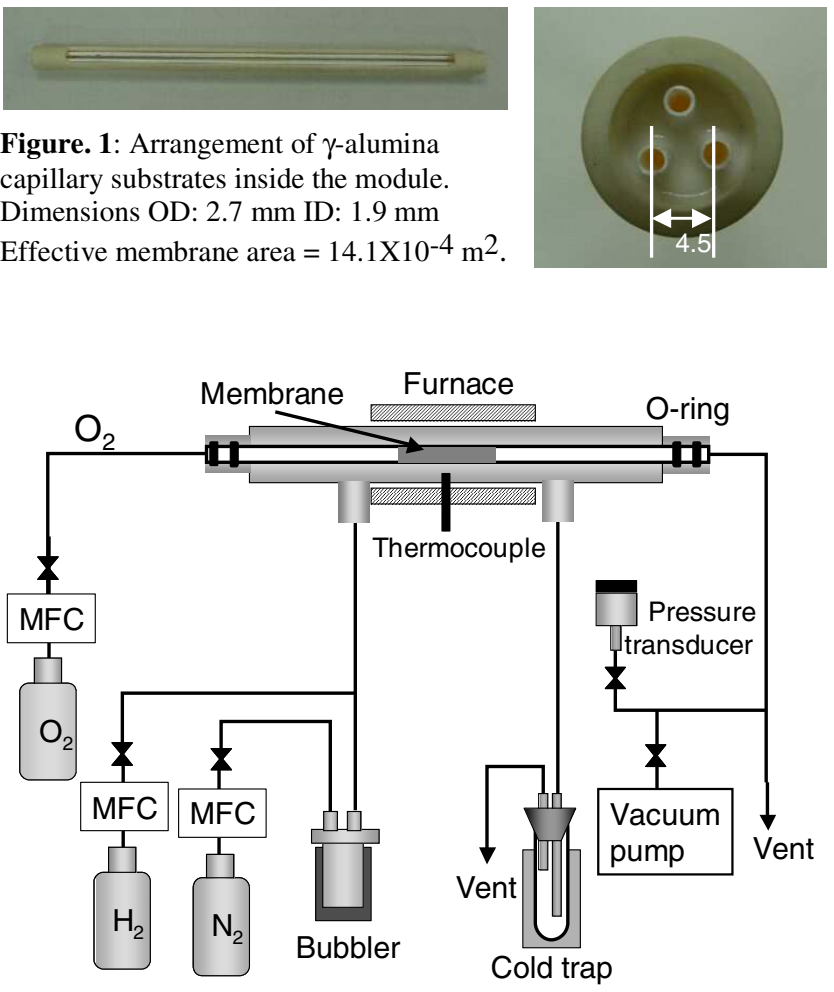

Figure 2: Scheme showing the CVD experimental setup. diffusion) at $873 \mathrm{~K}$. After $2 \mathrm{~h}$ of reaction, nitrogen was purged for some time to remove excess TMOS from the reactor. The inner side of the module was then kept under vacuum for about 1 hour to stabilize the system. For making the capillary membranes, the modular substrate was replaced by single capillary substrate following the same procedure as described above. Similarly, sol-gel silica layers were prepared by dip coating process, the silica sol for which was made by the hydrolysis of tetra-ethyl-ortho-silicate. The membranes were dried at $313 \mathrm{~K}$ (humidity $60 \%$ ) and sintered at $873 \mathrm{~K}$. Further details on the preparation of the sol and the processing of the membrane could be found elsewhere [5].

\section{Permeation measurements}

Single component gas permeation measurements were made for various gases at $873 \mathrm{~K}, 773 \mathrm{~K}$ and $373 \mathrm{~K}$. Single component gas molecules were allowed to flow through the outer side of the module at ambient pressure conditions. Permeate side of the module was kept under vacuum and the change in pressure inside a constant-volume tank is measured with time to derive the permeance values.

\section{RESULTS AND DISCUSSION}

Performance of $\mathrm{H}_{2}$ and $\mathrm{N}_{2}$ through a single, short capillary membrane is given in Fig. 3. This membrane had an effective membrane area of $4.7 \times 10^{-4} \mathrm{~m}^{2}$ and the $\mathrm{H}_{2}$ permeance through this membrane was $1.41 \times 10^{-7} \mathrm{~mol} \mathrm{~m} \mathrm{~m}^{-2} \mathrm{~s}^{-1} \mathrm{~Pa}^{-1}$ with a permselectivity over $\mathrm{N}_{2}$ of 9600 at $873 \mathrm{~K}$. Activated transport displayed by the $\mathrm{H}_{2}$ molecules $\left(E_{\mathrm{a}}=23.56 \mathrm{~kJ}\right)$ indicates that the average pore size of this membrane was small enough to allow the passage of smaller molecules while effectively blocking larger $\mathrm{N}_{2}$ molecules. The stability of this membrane under hydrothermal conditions is given in Fig. 4. Steam was introduced as $\mathrm{H}_{2} \mathrm{O} / \mathrm{N}_{2}$ mixture at $773 \mathrm{~K}$ with a $\mathrm{H}_{2} \mathrm{O} / \mathrm{N}_{2}$ ratio of 3 , thereby simulating membrane reactor conditions. The membrane remained stable for $\sim 35 \mathrm{hrs}$, maintaining a

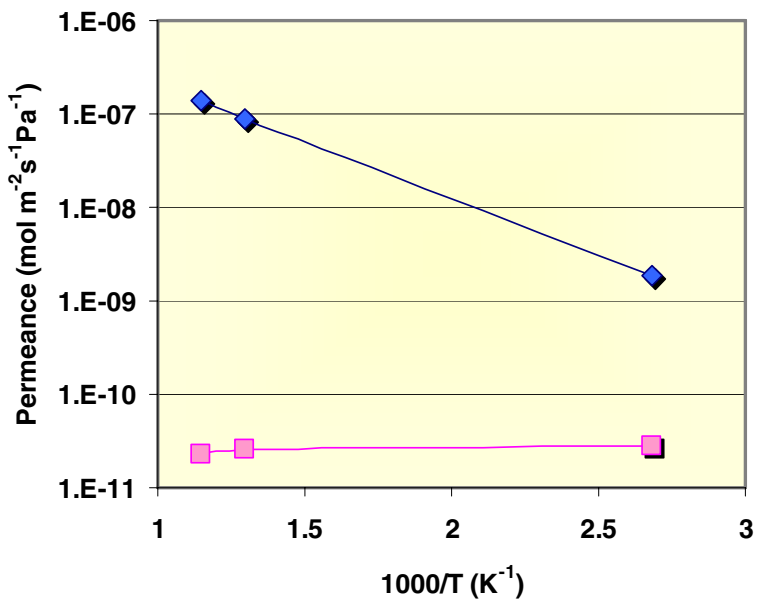

Figure 3: Permeance of $\mathrm{H}_{2}$ and $\mathrm{N}_{2}$ through a single, short capillary membrane with temperature. 


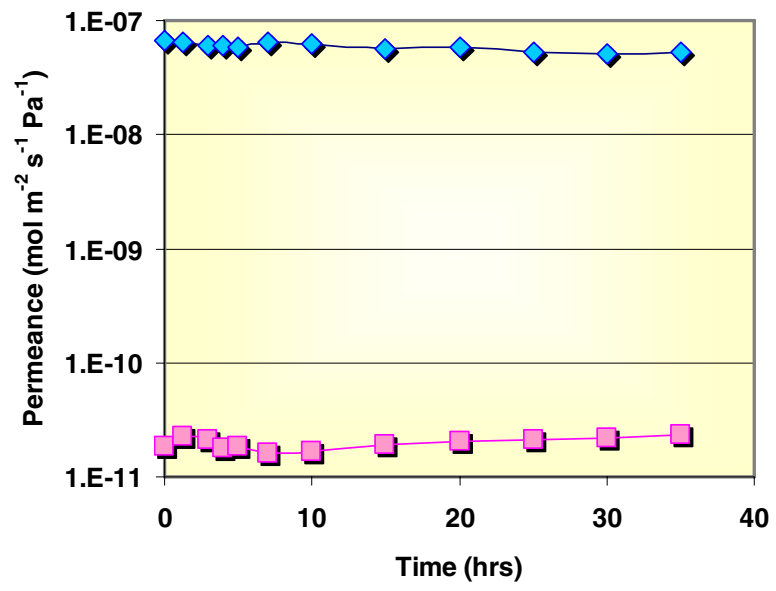

Figure 4: Hydrothermal stability at $773 \mathrm{~K}$ under $\mathrm{H}_{2} \mathrm{O} / \mathrm{N}_{2}=3$ and $K_{\mathrm{p}}=76 \mathrm{KPa}$.

separation of 2200 for this period of time. Usually, silica membranes are prone to reaction with $\mathrm{H}_{2} \mathrm{O}$ and become dense, which results in reduced selectivity. But the maintanence of selectivity for this membrane indicates to the fact that the silica deposition might have formed well within the narrow mesopores of the gamma-alumina substrate.

In order to evaluate the consistancy in membrane formation process, the membrane area was increased to $2.17 \times 10^{-3} \mathrm{~m}^{2}$ and the performance of this single, long-capillary membrane is given in Fig. 5. $\mathrm{H}_{2}$ permeance through this membrane was $1.61 \times 10^{-7}$ mol m$~^{-2} \mathrm{~s}^{-1} \mathrm{~Pa}^{-1}$ with a permselectivity over $\mathrm{N}_{2}$ of 3100 at $873 \mathrm{~K}$. Activation energy measured for $\mathrm{H}_{2}$ through this membrane was $22.01 \mathrm{~kJ}$, confirming the reproducibility of the membrane formation process. But this membrane tends to deteriorate resulting in a reduction of performance when subjected to hydrothermal conditions as described earlier. This may be due to the fact that membrane formation was not uniform for the entire membrane length due to the varying

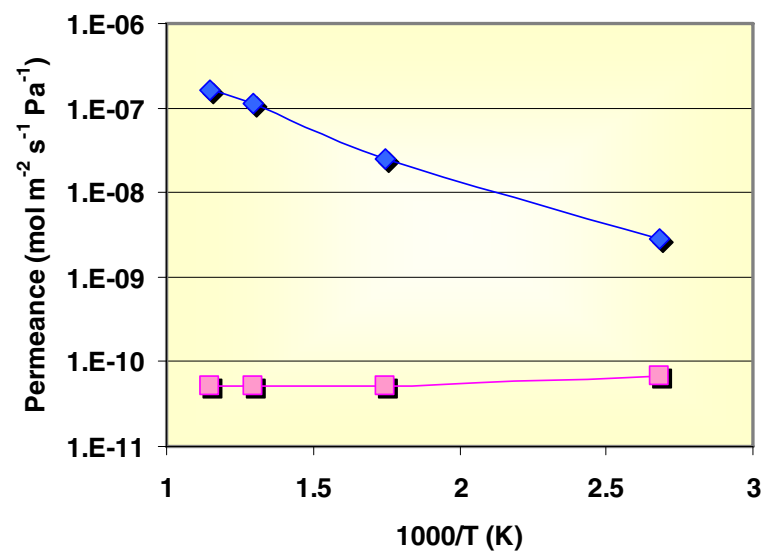

Figure 5: $\mathrm{H}_{2}$ and $\mathrm{N}_{2}$ permeance through single, long-capillary membrane with temperature.

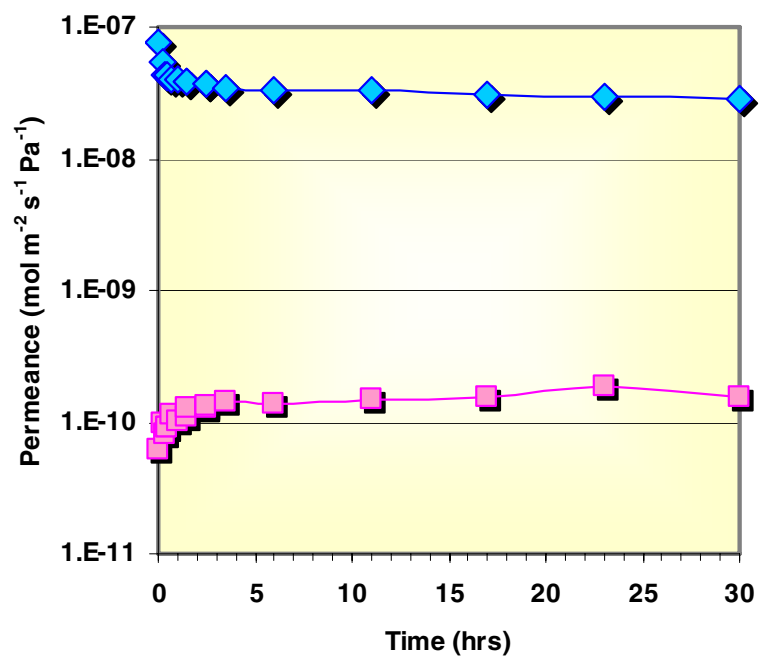

Figure 6: Hydrothermal stability at $773 \mathrm{~K}$ under $\mathrm{H}_{2} \mathrm{O} / \mathrm{N}_{2}=3$ and $K_{\mathrm{p}}=76 \mathrm{KPa}$.

temperature profile as well as the distribution of the reactants inside the synthesis cell. But the consistancy achieved after 5 hours of exposure under steam conditions indicates the membrane stability under harsh conditions and by optimising formation conditions inside the cell could lead to the formation of better membranes.

To evaluate the formation process on multiple substrates, a membrane module was prepared by arranging three capillary short-substrates inside a dense casing as shown in Fig. 1. Silica was deposited simultaneously on all the three substrates using CVD procedure and the performance of this module is given in Fig. 7. It is interesting to note that, all the substrates received an even deposition through out the available membrane area given the complex flow profiles existing inside the module. $\mathrm{H}_{2}$ permeated at the rate of $4.4 \times 10^{-8}$ mol $\mathrm{m}^{-2} \mathrm{~s}^{-1} \mathrm{~Pa}^{-1}$, which was an order of magnitude lower than the single element membranes. But the activated transport displayed by $\mathrm{H}_{2}\left(E_{\mathrm{a}}=22.74 \mathrm{~kJ}\right)$ and a selectivity of $\sim 3000$ over $\mathrm{N}_{2}$ at $873 \mathrm{~K}$ assures the intact nature fo the membrane formed. It may be that the distribution of the reactants inside the module need not be uniform - the outer visible membrane regions receving more reactants than the inner, invisible axial regions, thereby creating a concentration gradient inside the module. Moreover, as the available membrane area increases, there will be an increase in the initial $\mathrm{O}_{2}$ flow, which could result in reactions happening near the pore openings as well, producing thicker deposits in these regions that ultimately behaves as thicker membranes. These thicker pore mouths adversely affect permetion and also the membrane stability under hydrothermal conditions. Another module with an initial $\mathrm{H}_{2} / \mathrm{N}_{2}$ selectivity of $\sim 1000$ was tested under hydrothermal conditions and its performance is given in Fig. 8. Under steam conditions, this module displayed an initial reduction in their selectivity, which later stabilized after $30 \mathrm{~min}$. of exposure and remained stable thereafter for $\sim 15 \mathrm{hrs}$ of testing in the 


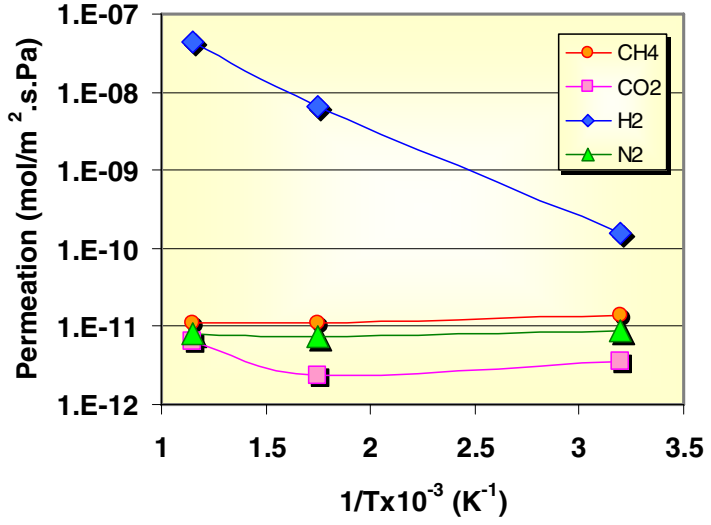

Figure 7: $\mathrm{H}_{2}$ and $\mathrm{N}_{2}$ permeance through membrane module with temperature.

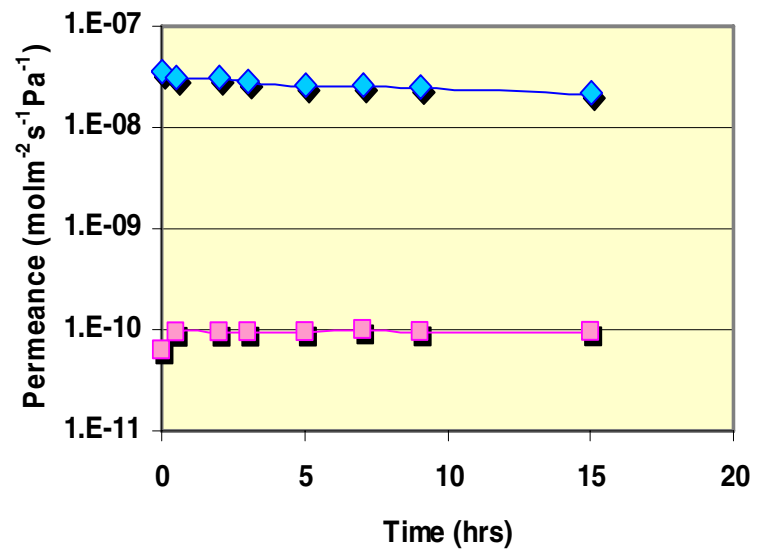

Figure 8: Hydrothermal stability of three-element module at $773 \mathrm{~K}$ under $\mathrm{H}_{2} \mathrm{O} / \mathrm{N}_{2}=3$ and $K_{\mathrm{p}}=76 \mathrm{KPa}$.

laboratory. The initial drop in performance is due to the densification of the silica deposits near the pore-mouths but the deposit formed inside the substrate pores remained stable as displayed by the stable performance later in the test.

A rapid hybrid processing method was used to improve the permeation and separation properties. This new process involved both sol-gel as well as CVD methods; sol-gel method giving precise control of the membrane pore structure while CVD imparts a homegenous deposit inside these pores to achieve better permselectivity. Usually, obtaining very large permselectivity values are difficult with sol-gel membranes and getting large permeation values are difficult with CVD membranes. The new hybrid membrane prepartion procedure could derive a membrane with high permeation and separation values, at a surprisingly short CVD duration of 5minutes. The permeation of $\mathrm{H}_{2}$ and $\mathrm{N}_{2}$ through a typical hybrid membrane is given in Table I. As shown in the table, the performance of the membranes are better than the sol-gel or CVD counterparts.
TABLE I. SINGLE GAS PERMEANCES OF $\mathrm{H}_{2}$ AND $\mathrm{N}_{2}$ THROUGH SILICA MEMBRANES AT $873 \mathrm{~K}$.

\begin{tabular}{|c|c|c|c|}
\hline Membrane & $\begin{array}{c}\mathrm{H}_{2} \\
\left(\mathrm{~mol} \mathrm{~m}^{-2} \mathrm{~s}^{-1} \mathrm{~Pa}^{-1}\right)\end{array}$ & $\begin{array}{c}\mathrm{N}_{2} \\
\left(\mathrm{~mol} \mathrm{~m}^{-2} \mathrm{~s}^{-1} \mathrm{~Pa}^{-1}\right)\end{array}$ & $\mathrm{H}_{2} / \mathrm{N}_{2}$ \\
\hline Sol-gel [5] & $7.40 \times 10^{-7}$ & $7.30 \times 10^{-9}$ & 102 \\
\hline CVD & $1.41 \times 10^{-7}$ & $1.46 \times 10^{-11}$ & 9650 \\
\hline Hybrid & $6.43 \times 10^{-7}$ & $2.74 \times 10^{-10}$ & 2346 \\
\hline
\end{tabular}

\section{CONCLUSION}

Hydrogen permselective membranes were prepared using chemical vapor deposition procedure over a $\gamma$-alumina coated capillary substrates. $\mathrm{H}_{2}$ permeation was faster through membranes with smaller area than larger membranes, may be due to the difference in their formation. These membranes also displayed excellent stability under membrane reactor conditions. Membrane modules prepared by arranging three short capillary membranes inside a dense casing also displayed excellent performance with much better stability under hydrothermal conditions. A novel hybrid membrane processing method studied also resulted in membranes with excellent performance within a very short preparation time, without compromising the permeance of gases and permselectivity.

\section{ACKNOWLEDGMENT}

S. G. would like to acknowledge the financial support from The Centre for Low Emission Technology (cLET) and The Australian Research Council (ARC) under its Executive Research Scheme. This work is performed as part of the R\&D Project for High efficiency Hydrogen Production/Separation system using Ceramic Membranes funded by NEDO, Japan.

\section{REFERENCES}

[1] J. J. Romm, "The hype about hydrogen : fact and fiction in the race to save the climate," Island Press, Washington DC, p. 238, 2004.

[2] M. Nomura, M. Seshimo, H. Aida, K. Nakatani, S. Gopalakrishnan, T. Sugawara, T. Ishikawa, M. Kawamura, S. I. Nakao, "Preparation of a catalyst composite silica membrane reactor for steam reforming reaction by using a counter diffusion CVD method," Ind. Eng. Chem. Res. 2006, 45, 3950-3954.

[3] B. N. Nair, T. Yamaguchi, T. Okubo, H. Suematsu, K. Keizer, S. I Nakao, "Sol-gel synthesis of molecular sieving silica membranes," J. Membr. Sci. 1997, 135, 237-243.

[4] B. N. Nair, K. Keizer, W. J. Elfernik, M. J. Gilde, H. Verweij, A. J. Burggraaf, "Synthesis, characterisation and gas permeation studies on microporous silica and alumina-silica membranes for separation of propane and propylene,” J. Membr. Sci. 1996, 116, 161-169.

[5] Y. Yoshino, T. Suzuki, B. N. Nair, H. Taguchi, N. Itoh, "Development of tubular substrates, silica based membranes and membrane modules for hydrogen separation at high temperature," J. Membr. Sci. 2005, 267, $8-17$.

[6] G. Suraj, K. Ono, M. Nomura, T. Sugawara, S. Nakao, "Microporous silica membraneprepared using TMOS/O3 CVD in opposing reactants geometry," Trans. Mat. Res. Soc. Japan, 2004, 29, 3263-3266.

[7] S. Gopalakrishnan, M. Nomura, T. Sugawara, S. I. Nakao, "Preparation of a multi-membrane module for high temperature hydrogen separation," Desalination, 2006, 193, 230-235. 